\title{
MATHEMATICAL RELATIONS OF MODELS OF SINGLE-PHASE FLOWS IN THE CHANNELS OF REACTORS AND STEAM GENERATORS OF NPP'S FOR CALCULATION OF HEAT TRANSFER PROCESSES AND HYDRODYNAMIC CHARACTERISTICS
}

\author{
O.V. Yefimov ${ }^{1}$, M.M. Pylypenko ${ }^{2}$, V.L. Kavertsev ${ }^{1}$, T.A. Harkusha ${ }^{1}$, \\ L.J. Tiutiunyk ${ }^{1}$, A.V. Motovilnik ${ }^{1}$ \\ ${ }^{1}$ National Technical University "Kharkiv Polytechnic Institute”, Kharkiv, Ukraine \\ E-mail: AVEfimov@kpi.kharkov.ua; \\ ${ }^{2}$ National Science Center "Kharkov Institute of Physics and Technology”, Kharkiv, Ukraine
}

\begin{abstract}
The article presents the mathematical relationships of models of single-phase flows in channels of a other design for calculating the parameters of heat transfer processes and hydrodynamic (gas-dynamic) characteristics of flows. A comparative analysis of these ratios and their differences are indicated depending on the design of the channels. To calculate the processes of heat exchange in steam generators of nuclear power plants during the movement of single-phase flows of the coolant and working substance, the criterion equations of the similarity theory are used, which describe the generalized relationships between the quantities characterizing the processes that are similar to each other. These are the criteria for $\mathrm{Re}$; $\mathrm{Nu}$; Pr; Pe, et al. The article provides generalized relationships between similarity criteria for single-phase flows of different types of coolants (water, gas, liquid metals) and working substances that are used in the design and construction of reactors and steam generators.
\end{abstract}

\section{INTRODUCTION}

The efficiency, reliability and safety of reactor and steam generators of nuclear power plants are largely determined by the intensity and conditions of convective heat transfer processes in reactors and steam generators and hydrodynamic (gas-dynamic) characteristics of coolant and working substance flows [1-3].

\section{CALCULATION OF HEAT EXCHANGE PROCESSES AND HYDRODYNAMIC CHARACTERISTICS}

It is known that when flowing through heat transfer surfaces single-phase flows (flows of matter with a constant physical state of the medium) depending on their hydrodynamic characteristics, there are three possible flow regimes with different patterns of convective heat transfer: laminar flow, transient and turbulent flow. Laminar flow is formed in the case of predominance in the moving singlephase flow of viscosity forces. In this case, the trajectories of the particles in the flow are almost parallel to each other. If the moving single-phase flow is dominated by inertial forces, then there is a turbulent flow, which is characterized by radial mixing of the layers or vortex motion between adjacent layers. The relationship between the viscosity forces and the inertial forces in a moving single-phase flow is characterized by such a hydrodynamic (gas-dynamic) characteristic as the Reynolds number (Re).

With longitudinal flow around the heat transfer surfaces, the laminar flow regime exists at $\operatorname{Re} \leq 2300$, transient mode occurs when $2300<\mathrm{Re} \leq 10000$, turbulent flow mode - at $\operatorname{Re}>10000$.

When the transverse flow around the heat transfer surfaces, the laminar flow regime is formed at $\operatorname{Re} \leq 1000$, transient mode - when $1000<\operatorname{Re} \leq 10000$, turbulent flow regime occurs when $\operatorname{Re}>10000$.
Thus, the intensity of convective heat transfer is highest in the mode of turbulent flow. Therefore, NPP steam generators are designed taking into account the provision of, as a rule, turbulent flow of single-phase flows of coolant and working substance [1-8].

The processes of heat exchange and hydrodynamic (gas-dynamic) characteristics of flows in steam generators of NPPs with PWPR are significantly influenced by other physicochemical processes occurring in steam generators. These are, first of all, the processes of corrosion of structural materials and the transition of corrosion products in the coolant and feed water, as well as the processes of formation and deposition on the heat transfer surfaces of scale and removal of feed water impurities together with steam.

The processes of formation and deposition on the heat transfer surfaces of scale and removal of impurities of feed water together with steam are due to certain factors. The feed water at the entrance to the economizer areas of the heat transfer surfaces of steam generators contains a number of mineral and gaseous compounds (impurities) in the form of solutions. During vaporization in the evaporating areas of steam generators evaporation of solutions of these compounds and, at certain values of vapor content and characteristics of the steam-water mixture, begins the process of formation and deposition of some of these compounds in the form of scale on the heat exchanger surfaces. Part of the feed water impurities is carried together with moist saturated steam in the superheated areas of the heat exchange surfaces of steam generators, where it is also partially deposited in the form of scale.

The scale together with the steam also gets into the flowing parts of the turbine cylinders, where it is deposited on the surfaces of the guides and blades, thereby reducing the efficiency of the turbine stages. In steam generators of NPPs with multiple circulation of 
steam-water mixture, there are two types of removal of feed water impurities together with wet steam: the first is the transfer of impurities together with moisture particles, and the second - the transfer of impurities dissolved in steam.

Deposition of corrosion products of structural materials and scale of feed water impurities on the heat exchange surfaces of NPP steam generators reduces the efficiency of heat exchange processes, degrades the hydrodynamic (gas-dynamic) characteristics of coolant and working substance flows, reduces efficiency, reliability and safety of reactor and steam generators [9-11]. The impact of these processes on the reliability and safety of reactor and steam generators of nuclear power plants is explained by a number of factors. For example, in the case of exceeding the values of the heat transfer surfaces of steam generators above the upper (permissible) limits of the application temperatures of their structural materials, the mechanical (strength) properties of these materials deteriorate, which can lead to accidents. Reducing the efficiency of heat transfer processes and deteriorating hydrodynamic characteristics of coolant flows in steam generators impairs the process of heat removal from the coolant of the primary circuit to the working substance, resulting in increased coolant inlet temperature and reduced cooling efficiency, which in some cases can lead to accidents. Emergencies can be caused by alternating temperature voltage in the walls of the tubes of heat transfer surfaces as a result of pulsations of coolant and working substance flow, which are significantly enhanced by the deposition of corrosion and scale on the heat transfer surfaces of NPP steam generators.

The listed features of the course of convective processes of heat exchange in steam generators and hydrodynamic (gas-dynamic) characteristics of flows of the heat carrier and working substance need to be considered at designing and designing of reactor and steam generating installations of the NPP.

To calculate the processes of heat transfer in reactors and steam generators of NPPs during the movement of single-phase flows of coolant and working substance, the criterion equations of the theory of similarity are used, which describe the generalized dependences between quantities characterizing similar processes. Consider the main dimensionless criteria of the theory of similarity, which are used to calculate the processes of heat transfer in steam generators, their characteristics and the relationship between them.

Reynold's criterion. It is a measure of the ratio of the forces of inertia to the viscosity forces in the flows of the coolant or the working substance moving in the channels (tubes) of the steam generator. The Reynold's criterion is defined by the expression

$$
\operatorname{Re}=\frac{w d}{v}=\frac{w d \rho}{\mu},
$$

where $w$ - the flow rate of the coolant or working substance, $\mathrm{m} / \mathrm{s} ; d$-determining (characteristic) linear size of the channel, which is conditionally equal to the equivalent hydraulic diameter of the channel (inner diameter of the tube), m; $v$ - kinematic viscosity of the coolant or working substance, $\mathrm{m}^{2} / \mathrm{s} ; \mu-$ dynamic viscosity of the coolant or working substance, $\mathrm{Pa} \cdot \mathrm{s} ; \rho-$ density of the heat carrier or working substance, $\mathrm{kg} / \mathrm{m}^{3}$.

If we depict the Reynolds test in the form

$$
\operatorname{Re}=\frac{\rho w^{2}}{\mu(w / d)},
$$

then it is interpreted as a measure of the relative intensity of molar and molecular processes of transfer of the amount of motion.

Nusselt's criterion. It characterizes the increase in the intensity of heat transfer between the flow of coolant and the surface of the wall of the channel (tube) of the steam generator due to convection in comparison with the net thermal conductivity in a stationary medium. Nusselt's criterion is defined by the expression

$$
\mathrm{Nu}=\frac{\alpha \cdot d}{\lambda},
$$

where $\alpha$ - heat transfer coefficient from the heat carrier to the wall of the channel (tube), $\mathrm{W} /\left(\mathrm{m}^{2} \cdot \mathrm{K}\right) ; \lambda$ - thermal conductivity of the wall material of the channel (tube), $\mathrm{W} /(\mathrm{m} \cdot \mathrm{K})$.

Prandtl's criterion. It can be considered as the ratio of two characteristics of the processes of molecular transfer of the amount of motion and the amount of heat - kinematic viscosity, which characterizes the process of transfer of the amount of motion in the coolant flow, and the thermal conductivity of the channel wall (tube) thermal conductivity. Prandtl's criterion is defined by an expression

$$
\operatorname{Pr}=\frac{v}{a}=\frac{\mu \cdot c_{p}}{\lambda}
$$

where $a$ - thermal conductivity coefficient of the channel wall material (tube), $\mathrm{m}^{2} \cdot \mathrm{s} ; c_{p}$ - specific isobaric heat capacity, $\mathrm{J} /(\mathrm{kg} \cdot \mathrm{K})$.

Since the process of transferring the amount of motion is due to the difference in velocities, and the process of transferring the amount of heat - the difference in temperature, the Prandtl criterion characterizes the relationship between the velocity field and the temperature field.

Peclet's criterion. It is a measure of the relative intensity of molar and molecular heat transfer processes. It can also be considered as a measure of the ratio of the amount of heat transferred by the flow of coolant to the amount of heat transferred by the thermal conductivity of the material of the wall of the channel (tube) of the steam generator. Peclet's criterion is defined by the expression

$$
\mathrm{Pe}=\frac{w d}{a}=\frac{w c_{p} \rho}{\lambda / d}=\operatorname{Re} \operatorname{Pr} .
$$

The relationship between the similarity criteria for single-phase flows of different coolants and working substances in steam generators, except for liquid metals, is determined by the following generalized equation:

$$
\mathrm{Nu}=c \cdot \operatorname{Re}^{n} \operatorname{Pr}^{m},
$$

where $c, n, m$ - constant dimensionless quantities. 
For liquid metals, this ratio is determined by another generalized equation:

$$
\mathrm{Nu}=A+B(\operatorname{Re} \cdot \operatorname{Pr})^{k},
$$

where $A, B, k$-constant dimensionless quantities.

At the turbulent mode of movement of streams of heat carriers in tubes of steam generators of the NPP, at $\operatorname{Re}>10000$, the heat transfer coefficient from the coolant to the inner surface of the walls of the tubes is determined by the formula

$$
\alpha=0.021 \cdot(\lambda / d) \cdot \operatorname{Re}^{0.8} \operatorname{Pr}^{0.43} C_{t} C_{l} .
$$

In formula (7) the coefficient $C_{t}$, taking into account the change in the thermophysical properties of the coolant in the cross section of the flow, is equal to

$$
C_{t}=\left(\mathrm{Pr}_{m i d} / \mathrm{Pr}_{w}\right)^{0.25},
$$

where $\operatorname{Pr}_{\text {mid }}, \operatorname{Pr}_{w}-$ Prandtl criteria, respectively, calculated by the values of the parameters of the thermophysical properties of the medium of the coolant at a temperature in the middle of its flow and at a flow temperature equal to the temperature of the inner surface of the walls of the tubes. At a temperature of a stream of the heat carrier more than $200{ }^{\circ} \mathrm{C}$ that is characteristic of the majority of designs of modern reactors and steam generators of the NPP, $C_{t} \approx 1$.

Coefficient $C_{l}$ in formula (7) depends on the value of the ratio of the length of the tubes $l$ to their inner diameter $d$. In most designs of modern steam generators $l / d>50$. In these cases $C_{l}=1$.

When the flow of coolant inside the tubes of the steam generator, the characteristic linear diameter included in formula (7) is equal to the inner diameter of the tubes. When the longitudinal flow of the coolant in the channel of any shape, it is equal to the equivalent hydraulic diameter, which is defined as

$$
d_{0}=4 \cdot f / \Pi \text {, }
$$

where $f$-cross-sectional area of the channel, $\mathrm{m}^{2} ; \Pi-$ full (wet table) perimeter of the channel, $\mathrm{m}$.

In the turbulent mode of movement of the coolant in the bent tubes of the steam generator, the coefficient of heat transfer to the walls of the tubes $\alpha_{\text {bent }}$ is slightly higher than the coefficient of heat transfer during the movement of the coolant in the straight tubes $\alpha$. It is determined by the ratio

$$
\alpha_{\text {bent }}=\alpha \cdot \varepsilon_{\text {bent }} \text {. }
$$

In this expression $\alpha_{\text {bent }}$ is the coefficient of intensification of the heat transfer process due to the movement of the coolant in the bent tubes. It is calculated by the formula

$$
\varepsilon_{\text {bent }}=1+1.8\left(d / R_{\text {bend }}\right),
$$

where $d$-inner diameter of the tubes, $\mathrm{m} ; R_{\text {bend }}-$ tube bending radius, $\mathrm{m}$.

In the designs of modern steam generators of NPPs, in which the working substance moves in the intertube space, the heat exchange surfaces are bundles of parallel tubes, which have a corridor or checkerboard arrangement (Fig. 1). The distances between the axes of the tubes $S_{1}$, which are located across the moving flow of the working substance, and the distances between the axes of the tubes $s_{2}$, which are located along the flow of the working substance, are called respectively transverse and longitudinal steps of the tube bundle. There is also a diagonal step for the checkerboard arrangement of the tube bundle $s_{d}$. The ratio of the steps of the tube bundle to the outer diameter of the tubes $d_{\text {out.t }}$ are called relative steps.

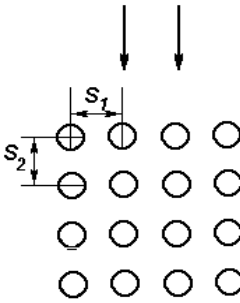

$a$

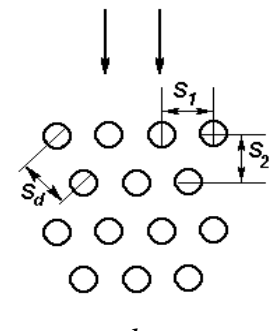

$b$
1. Location of tubes of heat exchange surfaces of NPP steam generators: $a$-corridor; $b$-chess

In NPP steam generators within one bundle of tubes the constancy of these geometrical characteristics remains.

Based on the data on the outer diameter of the beam tubes, their transverse and longitudinal steps, as well as data on the number of rows of tubes located across the flow of the working substance $z_{1}$, and the number of rows of tubes located along the movement of this flow $z_{2}$, heat transfer patterns are calculated.

For moving flows of working substance in the intertube space of the steam generator, in which $\operatorname{Re}>1000$, the average heat transfer coefficient from the heat transfer surface in the form of one row of tubes to the flow of the working substance is determined by the following equation:

$$
\alpha_{t}=c\left(\lambda / d_{\text {out. } t}\right) \operatorname{Re}^{n} \operatorname{Pr}^{0.33} C_{t} \cdot \varepsilon_{s} \cdot \varepsilon_{\psi} .
$$

In equation (12), the coefficients and the exponent at Re acquire the following values:

- for beams with a corridor arrangement of tubes

$$
c=0.26 ; n=0.65 \text {; }
$$

- for bundles with a checkerboard arrangement of tubes $c=0.41, n=0.60$;

$-\varepsilon_{s}-$ correction coefficient, taking into account the effect on the heat transfer coefficient of the values of the relative steps and the relationship between the steps of the tubes:

for beams with a corridor arrangement of tubes

$$
\varepsilon_{s}=\left(s_{2} / d_{\text {out.t }}\right)^{-0.15},
$$

for bundles with a checkerboard arrangement of tubes

$$
\begin{array}{ll}
\varepsilon_{s}=\left(s_{1} / s_{2}\right)^{0.17} \quad \text { at } \quad s_{1} / s_{2} \leq 2, \\
\varepsilon_{s}=12 \quad \text { at } \quad s_{1} / s_{2}>2 ;
\end{array}
$$


$-\varepsilon_{\psi}^{\prime}-$ correction factor that takes into account the effect on the heat transfer coefficient of the angle of attack (inlet) $\psi$ of the flow of working substance on the bundle of tubes. It is determined according to Table 1 .

Table 1

The value of the coefficient $\varepsilon_{\psi}^{\prime}$ for the bundles of tubes of the heat transfer surfaces

of NPP steam generators at different angles of attack of the flow of the working substance

\begin{tabular}{|c|c|c|c|c|c|c|c|c|c|}
\hline$\psi$, deg. & 90 & 80 & 70 & 60 & 50 & 40 & 30 & 20 & 10 \\
\hline$\varepsilon_{\psi}^{\prime}$ & 1 & 1 & 0.98 & 0.94 & 0.88 & 0.78 & 0.67 & 0.52 & 0.42 \\
\hline
\end{tabular}

Coefficient $C_{t}$ in formula (12), which takes into account the change in the thermophysical properties of the working substance in the cross section of its flow, is determined by formula (8). In this formula, the criteria $\operatorname{Pr}_{\text {mid }}, \operatorname{Pr}_{w}-$ Prandtl criteria, which are respectively calculated from the values of the parameters of the thermophysical properties of the medium of the working substance at a temperature in the middle of its flow and at a flow temperature equal to the temperature of the outer surface of the walls of the tubes.

Parameters and hydrodynamic (gas-dynamic) characteristics of single-phase flows of coolant and working substance in the form of feed water in the channels of reactors and steam generators of NPPs are determined in the process of hydraulic calculation. As a result of this calculation the following characteristics of flows are defined:

- driving pressures and flow velocities;

- the total pressure drop along the flow path;

- loss of flow pressure in different parts of the tract;

- local flow rates and local heat transfer intensity values;

- hydraulic characteristics of technical devices located in the flow path and provide a stable mode of operation of reactor and steam generators.

Hydrodynamic (gas-dynamic) characteristics of singlephase flows of coolants and working substances of reactors and steam generators of NPP's are very diverse, as they depend on the thermophysical properties and physical state of the moving medium, structural and geometric characteristics of flow channels and flow structure. It should be noted that the hydrodynamic (gasdynamic) characteristics of single-phase flows in reactors and steam generators, as well as the characteristics of heat transfer processes, determine their reliability and technical perfection, and the existing variety of structural schemes of reactors and steam generators creates the need to calculate hydraulic characteristics and with different modes of flow around the heat transfer surfaces.

In NPP reactors and steam generators, single-phase flows of coolant and working substance are forced into circulation. Single-phase flow indicates the influence of various forces, of which the most significant are the friction forces, which are due to the viscosity of the moving medium, which cause the hydraulic resistance of the flow $\Delta P_{f r}$. In addition, the channels through which the single-phase flow moves, have areas with varying cross-sections, turns, places cluttered with fasteners. In these sections of the channels, the flow undergoes local hydraulic resistance $\Delta P_{l o c}$. The sum of the resistances of friction forces and local resistances is the total value of the hydraulic resistance of the flow due to friction forces and local hydraulic resistances:

$$
\Delta P_{g}=\Delta P_{f r}+\Delta P_{l o c} \text {. }
$$

It should also be borne in mind that when supplying heat to a single-phase flow there is an increase in the volume of the latter and, as a consequence, a slight increase in speed along the length of the channel.

Acceleration of the flow is accompanied by an increase in the resistance of the flow by the value $\Delta P_{\text {flaccel }}$. For a constant mode of movement of a single-phase flow in the section of the channel of constant cross section, this value is

$$
\Delta P_{\text {fl.accel }}=w_{2}^{2} \rho_{2}-w_{1}^{2} \rho_{1},
$$

where $w_{1}, \rho_{1} \mathrm{i} w_{2}, \rho_{2}-$ respectively speed, $\mathrm{m} / \mathrm{s}$, and density, $\mathrm{kg} / \mathrm{m}^{3}$, the flow at the entrance to the channel and at the exit.

However, with those changes in the velocities of single-phase flows of the coolant and the working substance, which are usually observed in the areas of the channels of the heat transfer surfaces of reactors and steam generators, the value $\Delta P_{\text {fl.accel }}$ compared with $\Delta P_{g}$ small, and they can be neglected in a number of practical calculations.

In addition, when the lifting nature of the movement of a single-phase flow there is a hydraulic resistance due to the rise of the mass of the coolant or working substance to a certain height.

This resistance depends on the density of the flow medium and the difference in height of the beginning and end of the lifting section. It is called leveling resistance $\Delta P_{\text {level }}$.

When the lowering nature of the flow value $\Delta P_{\text {level }}$ will be negative.

Level resistance is defined as

$$
\pm \Delta P_{\text {level }}=g, \rho, \Delta h \text {, }
$$

where $g$ - acceleration of free fall, $\mathrm{m} / \mathrm{s}^{2} ; h$ - height of lifting (lowering) section, $\mathrm{m} ; \rho-$ the average density of the flow medium in the area, $\mathrm{kg} / \mathrm{m}^{3}$.

The height of the lifting (lowering) section is equal to $\Delta h=l \cdot \sin \gamma$, where $l-$ length of the channel section, $\mathrm{m} ; \gamma-$ the angle of the channel, deg.

In most designs of reactors and steam generators, sections of single-phase flow channels have relatively small values $\Delta h$, therefore the magnitude $\Delta P_{\text {level }}$ had in comparison with hydraulic resistance $\Delta P_{g}$, as well as 
magnitude $\Delta P_{\text {fl.accel }}$, and therefore, in a number of practical calculations they can be neglected.

Therefore, despite the fact that the total (total) resistance of single-phase flows in the channels is defined as

$$
\Delta P_{\Sigma}=\Delta P_{g}+\Delta P_{\text {fl.accel }} \pm \Delta P_{\text {level }},
$$

given the small values $\Delta P_{\text {fl.accel }}$ i $\Delta P_{\text {level }}$ compared to the size $\Delta P_{g}$, we can conclude that the main resistance to the motion of a single-phase flow is the hydraulic resistance, which is determined by the equation (13).

The resistance of the friction forces of a single-phase flow is given in equation (13) $\Delta P_{f r}$ in channels with constant transverse flow is determined by the following equation:

$$
\Delta P_{\mathrm{f} r}=\xi \frac{l}{d} \cdot \frac{\rho \cdot w^{2}}{2},
$$

where $w$ - the average flow rate in the channel, $\mathrm{m} / \mathrm{s} ; l, d-$ respectively the length and diameter of the channel, $\mathrm{m}$; $\xi$ - coefficient of friction during the movement of a single-phase flow.

Usually the coefficient of friction during the movement of a single-phase flow $\xi$ depends on the speed of the flow, i.e. on the mode of its movement, determined by the number $\mathrm{Re}$, the roughness of the walls of the channel $\delta_{\text {roug }}$ and flow medium (its thermophysical properties). However, starting coefficient of friction from a certain (threshold) value $\operatorname{Re} \geq \operatorname{Re}_{f l}$, coefficient of friction $\xi$ does not depend on the speed and properties of the flow medium, and is determined only by the relative roughness of the walls of the channel, which is the value $\delta_{\text {roug }} / r$, where $r-$ does not depend on the speed and properties of the flow medium, and is determined only by the relative roughness of the walls of the channel, which is the value $\operatorname{Re} \geq \operatorname{Re}_{f l}=120 d / \delta_{\text {roug }}$, which are characteristic of reactors and steam generators of NPP's, the coefficient of friction is determined by the formula

$$
\xi=\frac{1}{\left(1.74+2 \cdot \lg \frac{r}{\delta_{\text {roug }}}\right)^{2}} .
$$

Values of roughness of walls of the channels (tubes) made of various steels are various: for tubes from carbon steel $\delta_{\text {roug }}<0.1 \mathrm{~mm}$, for stainless steel tubes $\delta_{\text {roug }}<0.05 \mathrm{~mm}$. Due to corrosion processes occurring in the channels (tubes), their roughness during operation changes.

The local hydraulic resistances of single-phase flow motion are given in equation (13) $\Delta P_{l o c}$ are determined by the formula

$$
\Delta P_{l o c}=\xi_{l o c} \frac{\rho \cdot w^{2}}{2},
$$

where $\xi_{l o c}$ - coefficient of local hydraulic resistance.

Values of coefficients of local hydraulic resistance $\xi_{l o c}$ for the most typical geometric shapes of the channels are given in the Table 2.

Table 2

The values of the coefficients of local hydraulic resistance

\begin{tabular}{|l|c|}
\hline \multicolumn{1}{|c|}{ Type of local resistance } & $\xi_{\text {loc }}$ \\
\hline $\begin{array}{l}\text { Entrance to the tube from the collector } \\
(d>350) \text { or boiler }\end{array}$ & 0.5 \\
\hline $\begin{array}{l}\text { Exit from the tubes into the collector } \\
(d>350) \text { or in boiler }\end{array}$ & 1.0 \\
\hline $\begin{array}{l}\text { Entrance to or exit from the intertube } \\
\text { space }\end{array}$ & 1.5 \\
\hline Rotation in U-shaped channels & 0.5 \\
\hline $\begin{array}{l}\text { Rotate } 180^{\circ} \text { through the partition in the } \\
\text { intertube space }\end{array}$ & 1.5 \\
\hline Wrapping of partitions supporting tubes & 0.5 \\
\hline Rotation by $90^{\circ}$ in the intertube space & 1.0 \\
\hline
\end{tabular}

In the event of a sudden change in the cross-section of the channel, provided that its smaller cross-section is equal to $f_{\text {small }}$, and its larger cross-section is equal to $f_{\text {larg }}$, the coefficient of local hydraulic resistance is determined by the formula

$$
\xi_{\text {loc }}=\left(1-\frac{f_{\text {small }}}{f_{\text {larg }}}\right)^{2},
$$

or according to the graphs shown in the Fig. 2.

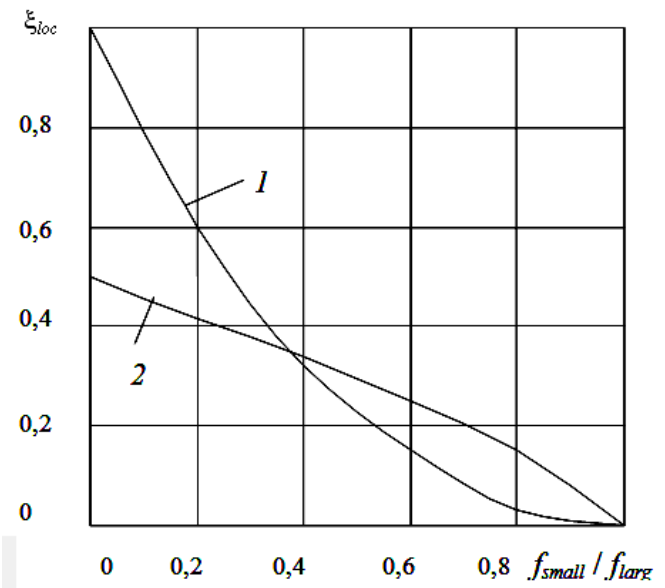

Fig. 2. Dependence of the change in the coefficient of local hydraulic resistance of single-phase flow with a sudden change in the cross-section of the channel:

1 - increase in cross section; 2 - reduction of section

When the longitudinal motion of a single-phase flow inside the channels of any geometric shape, the hydraulic resistance is determined by formulas (13), (17)-(19) by substituting in them the value of the equivalent hydraulic diameter calculated by the equation (9).

When longitudinal washing by a single-phase flow bundles of NPP steam generators, the equivalent hydraulic diameter $d_{0}$ is determined by the formula 


$$
d_{0}=\frac{\left(D_{\text {in } h}^{2}-n d_{\text {out }}^{2}\right)}{\left(D_{\text {in } h}^{2}+n d_{\text {out }}^{2}\right)},
$$

where $n$ - the number of tubes in the bundle; $D_{\text {in } h}$, $d_{\text {out } t}$ - respectively, the inner diameter of the steam generator housing and the outer diameter of the tubes, $\mathrm{m}$.

In the case of transverse washing by a single-phase flow of tube bundles of NPP steam generators, the basis of the hydraulic flow resistance is formed by alternating constrictions and the expansion of the cross section, so the resistance of the friction forces, which in this case is a small fraction, is not determined separately, and immediately calculates the total hydraulic resistance of the tube bundle

$$
\Delta P_{g . r}=\xi_{\text {bun }} \frac{\rho \cdot w^{2}}{2} \cdot \varepsilon_{\psi}^{\prime \prime},
$$

where $\xi_{\text {bun }}$ - the coefficient of hydraulic resistance of the pipe bundle during transverse washing, which depends on the design characteristics of the beam and flow modes; $\varepsilon_{\psi}^{\prime \prime}-$ correction coefficient taking into account the effect on the total hydraulic resistance of the angle of attack (inlet) $\psi$ of the flow on the pipe bundle.
The coefficient of hydraulic resistance $\xi_{\text {bun }}$ in formula (22) for pipe bundles with a corridor arrangement of tubes is determined by the formula

$$
\xi_{\text {bun }}=\left(6+9 \cdot z_{2}\right) \operatorname{Re}^{-0.28}\left(\frac{s_{1}}{d_{\text {out.t }}}\right)^{-0.28}
$$

and for beams with a checkerboard arrangement of tubes, it is determined by the following formulas:

$$
\begin{aligned}
& \xi_{\text {bun }}=\left(4+6.6 \cdot z_{2}\right) \operatorname{Re}^{-0.28} \text { at }\left(\frac{s_{1}}{d_{3}}\right) \leq\left(\frac{s_{2}}{d_{\text {out. }}}\right) ; \\
& \xi_{\text {bun }}=\left(5.4+3.4 \cdot z_{2}\right) \operatorname{Re}^{-0.28} \text { at }\left(\frac{s_{1}}{d_{3}}\right)>\left(\frac{s_{2}}{d_{\text {out.t }}}\right)
\end{aligned}
$$

In formulas (23)-(25) the number Re is determined by the flow velocity in the narrowest section of a number of tubes and the outer diameter of the tubes, and of tube the value $z_{2}$ - is the number of tubes in the beam in the direction of flow.

The value of the correction coefficient $\varepsilon_{\psi}^{\prime \prime}$ in formula (22) at different angles of attack of the singlephase flow on the tube bundle are shown in Table 3.

The value of the coefficient $\varepsilon_{\psi}^{\prime \prime}$ at different angles of attack of the flow on the tube bundle

of the heat transfer surfaces of NPP steam generators

\begin{tabular}{|l|c|c|c|c|c|c|c|c|}
\hline$\psi$, deg. & 90 & 80 & 70 & 60 & 50 & 40 & 30 & 10 \\
\hline$\varepsilon_{\psi}^{\prime \prime}$ & 1 & 1 & 0.98 & 0.94 & 0.88 & 0.78 & 0.67 & 0.42 \\
\hline
\end{tabular}

\section{CONCLUSIONS}

The given mathematical relations of models of single-phase flows in the channels of reactors and steam generators of NPPs can be effectively applied in computer programs of decision support systems at the stage of their design and operation.

\section{REFERENCES}

1. P.L. Kirillov, Yu.G. Yuriev, V.P. Bobkov. Handbook of thermohydraulic calculations (nuclear reactors, heat exchangers, steam generators). M.: "Energoatomizdat", 1990, 358 p.

2. A.I. Clemin, L.N. Polyanin, M.M. Strigulin. Teplohydraulic calculation and thermotechnical reliability of nuclear reactors. M.: “Atomizdat", 1980, 261 p.

3. A.M. Baklastov, V.A. Gorbenko, P.G. Removed. Design, installation and operation of heat and mass transfer installations. M.: "Energoizdat", 1981, 336 p.

4. A.V. Bezsonov, A.V. Zverev, V.A. Pharafons. The main equipment of nuclear power plants with PWPR reactors. Gorky: GTPI, 1981, $82 \mathrm{p}$.

5. V.M. Budov, A.V. Bezsonov, V.A. Pharafons. The main equipment of nuclear power plants. Gorky: GPI, 1979, $72 \mathrm{p}$.

6. V.M. Budov, S.A. Zamyatin, L.A. Zvereva. Heat exchange equipment of NPP. Gorky: GPI, 1983, 67 p.
7. V.M. Budov, V.A. Pharafons. Design of the main equipment of nuclear power plants. M.: "Energoizdat", 1985, $264 \mathrm{p}$.

8. O.V. Yefimov, M.M. Pylypenko, T.V. Potanina, V.L. Kavertsev, T.A. Harkusha. Reactors and steam generators of NPP power units: schemes, processes, materials, structures, models. Kharkiv: LTD "In fact", 2017, 420 p.

9. O.V. Yefimov, D.I. Kuhtin, T.V. Potanina, T.A. Harkusha, V.L. Kavertsev. Automated decision support system by operational personnel of NPP power units according to the criterion of technical and economic efficiency taking into account reliability indicators // Nuclear and radiation safety. 2018, N 2(78), p. 11-19.

10. O.V. Yefimov, M.M. Pylypenko, T.V. Potanina, T.O. Yesypenko, V.L. Kavertsev, T.A. Harkusha. Components of automated intellectual systems supporting decisions at the stage of operation and equipment diagnostics of nuclear power units // Problems of Atomic Science and Technology. 2020, N 1(125), p. 127-134.

11. O.V. Yefimov, M.V. Maksimov, Yu.V. Romashov. Loss of stability and the shape of possible bending of the guide channels of fuel assemblies for VVER1000 nuclear reactors // Nuclear and radioactivity safety. 2015, N 4(68), p. 14-19. 


\title{
МАТЕМАТИЧЕСКИЕ СООТНОШЕНИЯ МОДЕЛЕЙ ОДНОФАЗНЫХ ПОТОКОВ В КАНАЛАХ РЕАКТОРОВ И ПАРОГЕНЕРАТОРОВ АЭС ДЛЯ РАСЧЕТА ПРОЦЕССОВ ТЕПЛООБМЕНА И ГИДРОДИНАМИЧЕСКИХ ХАРАКТЕРИСТИК
}

\section{А.В. Ефимов, Н.Н. Пилипенко, В.Л. Каверцев, Т.А. Гаркуиа, Л.И. Тютюник, А.В. Мотовильник}

Представлены математические соотношения моделей однофазных потоков в каналах разного конструктивного исполнения для расчета параметров процессов теплообмена и гидродинамических (газодинамических) характеристик потоков. Проведен сравнительный анализ этих соотношений и указаны их отличия в зависимости от конструктивного исполнения каналов. Для расчета процессов теплообмена в парогенераторах АЭС при движении однофазных потоков теплоносителя и рабочего вещества применяют критериальные уравнения теории подобия, описывающие обобщенные зависимости между величинами, характеризующими сходные между собой процессы. Это критерии Re; $\mathrm{Nu}$; $\mathrm{Pr}$; $\mathrm{Pe}$ и др. Приведены обобщенные соотношения между критериями подобия для однофазных потоков теплоносителей различных видов (водяных, газовых, жидких металлов) и рабочих веществ, которые используются в практике проектирования и конструирования реакторов и парогенераторов.

\section{МАТЕМАТИЧНІ СПІВВІДНОШЕННЯ МОДЕЛЕЙ ОДНОФАЗНИХ ПОТОКІВ У КАНАЛАХ РЕАКТОРІВ І ПАРОГЕНЕРАТОРІВ АЕС ДЛЯ РОЗРАХУНКУ ПРОЦЕСІВ ТЕПЛООБМІНУ І ГІДРОДИНАМІЧНИХ ХАРАКТЕРИСТИК}

\author{
О.В. Сфімов, М.М. Пилипенко, В.Л. Каверцев, Т.А. Гаркуиа, Л.І. Тютюник, А.В. Мотовільник
}

Представлені математичні співвідношення моделей однофазних потоків у каналах різного конструктивного виконання для розрахунку параметрів процесів теплообміну i гідродинамічних (газодинамічних) характеристик потоків. Проведено порівняльний аналіз цих співвідношень і вказані їх відмінності в залежності від конструктивного виконання каналів. Для розрахунку процесів теплообміну в парогенераторах АЕС при русі однофазних потоків теплоносія i робочої речовини застосовують критеріальні рівняння теорії подібності, які описують узагальнені залежності між величинами, що характеризують подібні між собою процеси. Це критерії Re; $\mathrm{Nu}$; Pr; Pe та ін. Наведені узагальнені співвідношення між критеріями подібності для однофазних потоків теплоносіїв різних видів (водяних, газових, рідких металів) і робочих речовин, які використовуються в практиці проектування і конструювання реакторів і парогенераторів. 